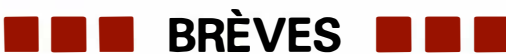

protéine ", active une phospholipase membranaire qui hydrolyse le pont phosphodiester d'un glycane-phosphatidyl-inositol. Le diacylglycérol ainsi formé pourrait activer la protéine kinase $\mathrm{C}$, expliquant ainsi probablement l'effet "prolifératif" de l'insuline. L'autre produit de la réaction, le glycane-inositol phosphate (qui pourrait exister sous une forme cyclique et une forme linéaire, expliquant l'existence de deux produits actifs), active la phosphodiestérase qui hydrolyse l'AMP cyclique en AMP, expliquant ainsi l'antagonisme entre l'insuline et les hormones activant l'adénylate cyclase (telles le glucagon, les agonistes $\beta$ adrenergiques, etc.).

A.K.

1. Molecular basis of insulin action. Czech, ed. Nex York: Plenum press, 1985.

2. Machicao E, Wieland O.H. Evidence that the insulin receptor-associated proteine kinase acts as a phosphatidylinositol-kinase. Febs lett 1984 ; 175 : 113.6

3. Saltiel AR, Fox AJ, Sherline P, Cuatrecasas $P$. Insulin-stimulated hydrolysis of a novel glycolipid generates modulators of cAMP phosphodiesterase. Science $1986 ; 233$ : 967-72.
- La sonde d'ADN complémentaire qui s'hybride avec le gène de la glucose 6 phosphate déshydrogénase sur le chromosome $\mathrm{X}$ reconnaît également un locus sur le chromosome 17. C'est ce que viennent de montrer Yoshida et Lebo. Il peut s'agir d'un pseudogène, mais aussi d'un gène fonctionnel pour l'isozyme décrit en 1982 dans le cerveau fotal, ou d'un isozyme particulier au cancer mammaire décrit chez la souris il y a dix ans et tombé depuis dans l'oubli.

[Yoshida A et al. Am J Hum Genet 1986 ; 39 : 203-6.]

La possibilité de pseudohermaphrodisme masculin par déficit en 5 alpha réductase était récemment décrite dans $\mathrm{m} / \mathrm{s} n^{\circ} 5$, vol. 2, p. 267 . Une véritable " épidémie " vient d'en être décrite dans un petit village de Turquie du Sud, où onze hommes (sur moins de 1000 ) en sont atteints, confirmant l'hérédité récessive autosomique du déficit. Les auteurs rappellent qu'un même phénomène avait été signalé en 1974 en République Dominicaine. [Akgun S et al. Am J Med 1986 ; $81: 267-74$.
[ L'administration orale d'insuline est peut-être possible, révolutionnant alors le traitement des diabétiques. Le principe consiste à inclure l'hormone dans des polymères dont les sous-unités sont couplées par l'intermédiaire de groupes aromatiques azoïques de formule générale

$$
R-\square-N=N-\square-R
$$

Ces structures protègent l'hormone dans l'estomac et l'intestin grêle, mais sont dégradées dans le colon où la flore microbienne réduit le pont azoïque $\mathrm{N}=\mathrm{N}$. $\mathrm{Au}$ niveau de ce dernier organe, l'insuline est donc libérée, n'est pas dégradée par les enzymes protéolytiques du suc digestif, et est partiellement absorbée. Des expériences préliminaires ont démontré qu'ainsi administrée l'insuline était en effet capable de réduire la glycémie d'animaux diabétiques.

[Saffran M et al. Science 1986 $233: 1091-4$.

\section{Génétique moléculaire de la phénylcétonurie}

Une mutation, cause de phénylcétonurie (PCU), vient d'être identifiée pour la premiere fois dans le gène de la phénylalanine hydroxylase humaine (PH). Le changement d'une guanine en adénine au site donneur d'un intron empêche l'épissage de l'ARN messager et la production de l'enzyme normale. Les auteurs ont mené une étude génétique approfondie au Danemark. Grâce au très grand polymorphisme de restriction au niveau du locus de la $P H$, ils ont pu définir huit haplotypes différents. La mutation identifiée, qui concerne $38 \%$ des PCU danoises, est liée de façon constante à l'haplotype 3 qui ne représente que $3 \%$ de la population. On peut conclure que cette mutation est $m / s n^{\circ} 1$ vol. 3 , janvier 87 née chez un individu porteur de l'haplotype 3 et s'est répandue ensuite par effet fondateur. Des essais préliminaires montrent que la même liaison est retrouvée dans des pays voisins, et l'hypothèse peut être soulevée qu'elle émane de l'Irlande, le pays où la fréquence de la PCU est la plus élevée. $A$ l'opposé, les PCU liées aux autres haplotypes ont des anomalies biochimiques différentes qui sont en cours d'exploration.

Ce travail ouvre des perspectives considérables. D'une part, en montrant la liaison génétique d'une mutation à un haplotype déterminé, il élève pour la première fois une enzymopathie à un niveau de connaissance réservé jusqu'à présent aux hémoglobinoses. D'autre part, sur le plan pratique, il est le premier jalon d'une méthode qui, étendue aux autres haplotypes, a pour ambition proclamée d'aboutir à la détection des porteurs sains du gène de la PCU dans la population générale, ce qui n'est pas réalisable actuellement. Une réserve doit cependant tempérer cet enthousiasme puisqu'il n'est pas certain que cette extension aux autres haplotypes se vérifie, ni qu'elle s'applique, comme le pensent les auteurs, à l'ensemble des "Caucasiens".

J.-C.D.

DiLella AG, Marvit J, Lidsky AS, Gūtler F, Woo SLC. Tight linkage between a splicing mutation and a specific DNA haplotype in

phenylketonuria. Nature $1986 ; 322: 799-803$.
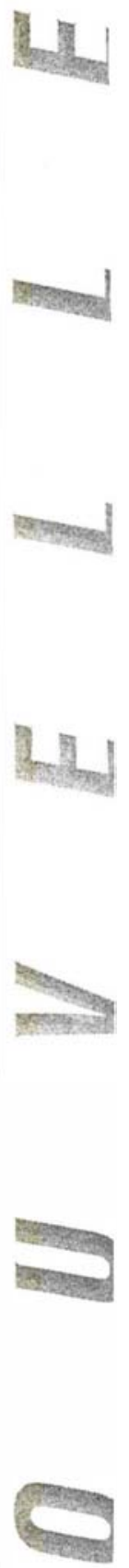